\title{
Developmental Toxicity of Inhaled Methyl Ethyl Ketone in Swiss Mice
}

\author{
B. A. SChWETZ,' T. J. MaSt, ${ }^{*}$ R. J. WeIGEL, ${ }^{*}$ J. A. Dill, ${ }^{*}$ ANd R. E. MorRisSeY ${ }^{2}$ \\ Developmental and Reproductive Toxicology Group, Division of Toxicology Research and Testing, \\ National Institute of Environmental Health Sciences, Research Triangle Park, North Carolina 27709; \\ and ${ }^{*}$ Battelle Pacific Northwest Laboratory, P.O. Box 999, Richland, Washington 99352
}

Received July 25, 1990; accepted December 28, 1990

\begin{abstract}
Developmental Toxicity of Inhaled Methyl Ethyl Ketone in Swiss Mice. SCHwETZ, B. A., Mast, T. J., Weigel, R. J., Dill, J. A., AND MorRissey, R. E. (1991). Fundam. Appl. Toxicol. 16, 742-748. Methyl ethyl ketone (MEK) is a widely used industrial solvent to which there is considerable human exposure. To assess the potential for MEK to cause developmental toxicity in rodents, groups of Swiss (CD-1) mice were exposed to 0, 400, 1000, or $3000 \mathrm{ppm}$ MEK vapors $7 \mathrm{hr} /$ day on Days 6-15 of gestation. Groups consisted of about 30 bred females each. Exposure of pregnant mice to these concentrations of MEK did not result in overt maternal toxicity although there was a slight, treatment-related increase in relative liver weight which was statistically significant in the $3000 \mathrm{ppm}$ group. Mild developmental toxicity was observed in the $3000 \mathrm{ppm}$ group in the form of a reduction in mean fetal body weight. This reduction was statistically significant for the males only, although the relative decrease from the control values was the same for both sexes. There was no increase in the incidence of resorptions or the number of litters with resorptions among mice exposed to MEK. There was no significant increase in the incidence of any single malformation, but several malformations which were not observed in the concurrent control group or the controls of contemporary studies were present at a low incidence-cleft palate, fused ribs, missing vertebrae, and syndactyly. There was also a significant trend for increased incidence of misaligned sternebrae, a developmental variation. In summary, pregnant Swiss (CD-1) mice were relatively insensitive to the toxic effects of MEK at the inhaled concentrations used in this study. However, the offspring of the mice exhibited significant signs of developmental toxicity at the $3000 \mathrm{ppm}$ exposure level. Neither maternal nor developmental toxicity was observed at 1000 ppm MEK or below. (c) 1991 Society of Toxicology.
\end{abstract}

Methyl ethyl ketone (MEK) is a widely used industrial solvent with a 1984 production figure of 556,000,000 lbs. (Yang, 1986, and references therein). Inhalation of MEK vapors and skin contact with liquid MEK are the major routes of human industrial exposure. The ACGIH (1988) has adopted a TLV of $200 \mathrm{ppm}$

\footnotetext{
${ }^{1}$ To whom all correspondence should be addressed at National Institute of Environmental Health Sciences, Chief, Systemic Toxicology Branch, P.O. Box 12233, MD D4-02, Research Triangle Park, NC 27709.

${ }^{2}$ Present address: Merck, Sharp \& Dohme Research Laboratories, Department of Safety Assessment, Building 45-1, West Point, PA 19486.
}

and a short-term exposure limit of $300 \mathrm{ppm}$ for MEK.

The toxicology literature on MEK has been thoroughly revicwed by Yang (1986). Animal studies have shown MEK to cause relatively little toxicity from acute or short-term repeated exposures. For example, a 90-day inhalation study of MEK in male and female F344 rats exposed to $0,1250,2500$, or $5000 \mathrm{ppm}$ MEK $6 \mathrm{hr} /$ day 5 days/week produced no adverse effects on the clinical health or growth of either sex (Cavender et al., 1983). While this study showed no evidence of neurotoxicity, MEK is known to potentiate $n$-hexane-induced neu- 
rotoxicity as well as that caused by other hydrocarbons (Altenkirch et al., 1978). MEK also potentiates the hepatotoxicity of chloroform. MEK has not been found to be mutagenic in mammalian or bacterial cell systems, but causes aneuploidy in yeast (Yang, 1986, and references therein).

The metabolism of MEK has been well characterized and is similar for all species examined-guinea pigs (Di Vincenzo et al., 1976), rats (Dietz and Traiger, 1979), rabbits (Sanoyeshi, 1911), and humans (Perbellini et al., 1984). The elimination half-life from serum was found to be $270 \mathrm{~min}$ following ip injection in guinea pigs (Di Vincenzo et al., 1976). MEK is well absorbed through the skin; Munies and Wurster (1965) reported the presence of MEK in expired air within 2-3 min following application of the solvent to the skin of humans. The rate of elimination from the blood is independent of the route or mode of exposure. Induction of the cytochrome P450 systems by MEK and/or its metabolites has been demonstrated by Abdel-Rahman et al. (1976). Toftgard et al. (1981) also found increased liver weights and cytochrome P450 content of the liver of rats exposed to $800 \mathrm{ppm}$ MEK for 6 hours/day 5 days/week for 4 weeks.

Developmental toxicity studies with MEK have been reported in rats. Schwetz et al. (1974) exposed timed-pregnant SpragueDawley rats to concentrations of 0,1000 , or 3000 ppm MEK on Days 6-15 of gestation. MEK exposure had no effect on resorptions, fetal crown-rump length, sex ratio, or on the maternal body weight or weight gain during gestation. Fetal body weight was slightly decreased for both exposure groups but the decrease was statistically significant only at the $1000 \mathrm{ppm}$ level. Major malformations were observed only at $3000 \mathrm{ppm}$-one fetus in each of four litters. Two of these fetuses were acaudate and two were brachygnathic. There was a significant increase in the percentage of litters having fetuses with reduced ossification of bones and extra ribs at both concentrations of MEK. The incidence of soft tissue anomalies (subcutaneous edema and dilated ureters) was also greater in the MEK-exposed groups than the controls and this increase was statistically significant in the $3000 \mathrm{ppm}$ group.

As a result of the findings of Schwetz et al. (1974), another study was conducted by Deacon et al. (1981), also in Sprague-Dawley rats. In this study, sperm-positive rats were exposed to 400,1000 , or $3000 \mathrm{ppm} \mathrm{MEK,} 7 \mathrm{hr} /$ day on Days 6-15 of gestation. The dams did not exhibit any clinical signs of toxicity but decreased weight gain and increased water consumption were observed at $3000 \mathrm{ppm}$. As in the earlier study, there was no significant effect on the mean number of live fetuses or resorptions per dam. The percentage of litters with fetuses exhibiting delayed ossification of vertebral centra was increased in the highest exposure group, as in the earlier study. Also as previously reported, the percentage of litters with fetuses having reduced ossification of skull bones was lower in the 3000 ppm exposure group than in any of the other groups. While the reduction in the incidence of reduced ossification of the skull bones is of uncertain importance, both studies supported a conclusion that developmental toxicity was observed-in the presence of maternal toxicity in one study and in its absence in the other.

Epidemiologic studies have also supported that exposure may be associated with adverse effects on human devclopment. Holmberg and Nurminen (1980) reported a statistically significant increase in the incidence of children born with central nervous system defects following maternal exposure to organic solvents during the first trimester of pregnancy when compared to children of unexposed mothers. MEK was among the organic solvents to which thc affected cohort was exposed. These authors further reported that no significant difference in the incidence of children with such defects was found when occupational exposures to metals, pesticides, dyes, noise, temperature extremes, fumes, or radiation were used as the analysis variable. Thus, because of the large number of people exposed to MEK and because the results of two studies in rats suggested that MEK may be a developmental toxicant, 
this study was conducted to evaluate the developmental toxicity of inhaled MEK in a second species of laboratory animal, Swiss (CD1) mice. The concentrations of MEK selected for this study were chosen to duplicate those used in a previous developmental toxicity study in rats (Deacon et al., 1981) and because $3000 \mathrm{ppm}$ was anticipated to be an appropriately high concentration for a study in mice.

\section{MATERIALS AND METHODS ${ }^{3}$}

Animals and animal husbandry. Four groups of female Swiss mice [(COBS) (CrI:CD-1)(ICR)BR Swiss Albino mice ${ }^{4} 12$ weeks of age at the beginning of the studies, were exposed to either filtered air as the control group or 400,1000 , or $3000 \mathrm{ppm}$ MEK vapors, $7 \mathrm{hr} /$ day for 10 consecutive days. Each of the four exposure groups consisted of 10 virgin and 33 plug-positive female mice. All groups were randomly selected using body weight as a blocking variable. Virgin mice were included to assess maternal toxic effects which may result solely from the state of pregnancy. The day of plug detection in mice was designated as Gestation Day 0. Pregnant mice were killed on Gestation Day 18 and virgin females were killed 3 days after the last exposure. Control animals were housed in an exposure chamber in the same room and were handled in the same manner as the mice that were exposed to MEK. Mice were housed in quarantine rooms for 4 weeks prior to start of exposures. Males and females were housed separately on stainless-steel wire racks equipped with automatic waterers. During the quarantine period, six males and four females were killed and examined for gross and microscopic lesions. Nasal pharyngeal washes from these animals were cultured for bacterial pathogens and serum from each animal was tested for antibodies to selected pathogens. Another check for antibodies was performed on serum obtained at the final euthanization from five females in the control and highest exposure groups. All results were negative for significant pathogens and lesions. Study animals were observed daily for mortality, morbidity, and overt signs of toxicity.

Food ${ }^{5}$ was provided free-choice during the entire time the animals were in the test facility except during the 7hr daily exposure when it was removed to prevent contamination. Room lighting was maintained on a 12-hr

\footnotetext{
${ }^{3}$ The NTP report of this study will be available through the National Technical Information Service. This study was conducted in accordance with FDA's Good Laboratory Practice, Regulations for Nonclinical Laboratory Studies (FDA, 1978).

${ }^{4}$ Charles River Breeding Laboratories, Raleigh, NC.

${ }^{5}$ NIH-07 diet, Ziegler Brothers, Inc., Gardner, PA.
}

cycle (0600-1800 for the light phase). Mean chamber temperatures during the study were maintained within the limits of $75 \pm 3^{\circ} \mathrm{F}$. Mean percentage relative humidity in all exposure chambers was within the specified limits of $55 \pm 15 \%$.

Test chemical and exposures. MEK (CAS No. 78-933) used for this study had an initial percentage purity greater than $99.9 \%$, confirmed by infrared spectrometry. For inhalation exposures, $2.3 \mathrm{~m}^{3}$ stainless-steel chambers were used which contained three levels of caging, each of which was split into two offset tiers. ${ }^{6}$ Filtered air containing a uniform mixture of MEK flowed through the chamber at approximately $15 \mathrm{ft}^{3}$ per min to provide 15 air changes per hour. Within the chambers, air flow, vacuum, temperature, relative humidity, and test chemical concentrations were monitored at approximately 4 -hr intervals. MEK vapor was generated by a rotary evaporation system which produced high purity MEK vapor. Nitrogen was introduced at low pressure to force MEK vapors out of the evaporator flask. The mixture of nitrogen and MEK were thoroughly blended with a conditioned air stream prior to entry into the chamber. Uniform distribution of the vapors in the chamber was confirmed. The concentrations of MEK in the chambers were monitored with a gas chromatographic system having an estimated precision of $\pm 1 \%$ and detection limit of $0.5 \mathrm{ppm}$. MEK was not found in the control chamber air or in the air surrounding the chambers in the exposure room.

Observations. Female mice were weighed at intervals of 3-5 days throughout the study. On Gestation Day 18, bred mice were killed with $\mathrm{CO}_{2}$, weighed, and examined grossly for signs of maternal toxicity. Maternal liver and kidney weights were recorded. Apparently nongravid uteri from mated females were stained with $10 \%$ ammonium sulfide to detect possible implantation sites. The number, position, and status of implants were recorded for each gravid uterus. Placentas were examined and discarded. Live fetuses were weighed and examined for gross defects, and their sex was determined by internal examination of the gonads after a lethal injection of Nembutal. Fifty percent of the live fetuses and any fetuses with gross external abnormalities were examined for visceral defects by dissection of fresh tissues. The heads of $50 \%$ of the live fetuses were removed and placed in Bouin's fixative. After fixation the heads were serial-sectioned with a razor blade and examined for soft tissue craniofacial abnormalities. All fetal carcasses were prepared for skeletal staining. Cartilage as well as ossified bone was visualized by double-staining with alcian blue and alizarin red $S$. The individual identity of each skeletal and head specimen was maintained throughout the study.

Statistical analyses. All means and standard deviations for animal data were analyzed using the SAS general linear models procedure (SAS, 1985) with an analysis of variance model for unbalanced data. Response variables, either body

\footnotetext{
${ }^{6}$ Harford System; Lab Products, Inc., Aberdeen, MD.
} 


\section{TABLE 1}

Summary of THE Methyl ETHyl Ketone Exposure Chamber Concentrations (ppm) During a DEVELOPMENTAL TOXICITY STUDY WTIH MICE

\begin{tabular}{lccc}
\hline & \multicolumn{3}{c}{ Exposure group (ppm) } \\
\cline { 2 - 4 } & 400 & 1000 & 3000 \\
\hline Mean \pm SD & $398 \pm 9$ & $1010 \pm 28$ & $3020 \pm 79$ \\
Maximum & 439 & 1140 & 3340 \\
Minimum & 352 & 894 & 2490 \\
\% Samples & & & \\
$\pm 10 \%$ of target & 100 & 98 & 99 \\
\hline
\end{tabular}

weight or the arcsin transformations of proportional incidence data, were analyzed against the class variable "treatment" in a one-way analysis of variance model. A Tukey's $t$ test (two-tailed) was used to assess statistically significant differences between control and exposed groups. If appropriate, the dose-response relationship was determined by means of an orthogonal trend test (Winer, 1971). In the case of proportional data, the $t$ tests and trend analyses were performed on transformed variables. The litter was used as the basis for analysis of fetal variables.

\section{RESULTS}

The average concentrations of MEK in the chambers during this study are summarized in Table 1. The average purity of MEK in unoccupied chambers and the distribution line to the chambers was $99.4 \%$ during test generation and $99.9 \%$ in chambers occupied by animals during the exposures. Thus, the techniques used to generate MEK vapor for the inhalation exposures did not affect its stability.

There were no differences in MEK toxicity between the virgin and pregnant female mice (data not shown). Therefore, the adult toxicity data referred to in the rest of this report is for the pregnant females. The mean pregnancy rate of the bred females was $82 \%$ with no significant difference in pregnancy rates between the MEK-exposed and the control groups. Mean body weights and weight gains were not affected by exposure to MEK at any time during the study when compared to the $0 \mathrm{ppm}$ group (Table 2). The relative liver weight of the $3000 \mathrm{ppm}$ group was significantly higher than the corresponding control relative liver weight. The relative kidney weight for the 3000 ppm group was also significantly greater than the control value; however, since the mean relative kidney weight was essentially the same for the 400 and the $3000 \mathrm{ppm}$ groups, and lower for the $1000 \mathrm{ppm}$ group, this change was probably not biologically important.

TABLE 2

Methyl Ethyl Ketone Mouse Developmental Toxicity Study: Mean Body AND ORGAN WEIGHTS, AND EXTRAGESTATIONAL WEIGHT GAINS

\begin{tabular}{|c|c|c|c|c|}
\hline & \multicolumn{4}{|c|}{ Exposure group (ppm) } \\
\hline & 0 & 400 & 1000 & 3000 \\
\hline Body wt & $\mathrm{n}=$ & 23 & 26 & 28 \\
\hline GD 6 & $28.8 \pm 1.7^{a}$ & $28.4 \pm 1.9$ & $28.8 \pm 1.8$ & $28.7 \pm 1.9$ \\
\hline GD 9 & $31.5 \pm 1.8$ & $31.2 \pm 2.1$ & $31.4 \pm 2.1$ & $31.8 \pm 2.0$ \\
\hline GD 15 & $44.7 \pm 3.4$ & $44.2 \pm 3.6$ & $44.0 \pm 3.3$ & $45.0 \pm 3.8$ \\
\hline GD 18 & $53.3 \pm 5.1$ & $52.2 \pm 5.1$ & $51.9 \pm 4.1$ & $53.0 \pm 4.9$ \\
\hline Extragestational wt gain ${ }^{b}$ & $6.9 \pm 1.4$ & $6.5 \pm 1.6$ & $6.5 \pm 1.9$ & $7.6 \pm 2.0$ \\
\hline Uterine wt & $20.1 \pm 3.6$ & $19.3 \pm 3.7$ & $18.8 \pm 2.9$ & $19.1 \pm 2.7$ \\
\hline \multicolumn{5}{|c|}{ Relative organ wt (g/100 g body $w t)$} \\
\hline liver & $5.28 \pm 0.61$ & $5.16 \pm 0.62$ & $5.41 \pm 0.36$ & $5.67 \pm 0.41^{*}$ \\
\hline kidney & $0.82 \pm 0.07$ & $0.87 \pm 0.11$ & $0.85 \pm 0.05$ & $0.87 \pm 0.07^{*}$ \\
\hline
\end{tabular}

${ }^{a}$ Grams, mean \pm SD.

${ }^{b}$ Maternal weight gain during gestation corrected for gravid uterine weight.

* Significantly different from control, $p<0.05$. 
Exposure of pregnant mice to MEK vapors on Gestation Days 6-15 did not affect the number of implantations or the percentage of live fetuses or intrauterine deaths per litter as compared to the controls (Table 3 ). Reductions in body weight of both male and female fetuses were significantly correlated with increasing concentrations of MEK, with the difference from control being statistically significant at $3000 \mathrm{ppm}$ for males but not at lower concentrations. However, both males and females body weights were lower than the control group by the same relative amount, about $4 \%$. The number of live fetuses per litter that were malformed and the number of litters with one or more malformed fetuses was increased in the MEK-groups compared to the controls but the differences were not statistically significant on the basis of either the number of fetuses or litters affected or the mean number of malformed fetuses affected per litter. However, there were four malformations (Table 4) observed in exposed groups that were not present in either the current control or in contemporary control groups. These malformations consisted of three fetuses with cleft palate (two in the $400 \mathrm{ppm}$ group and one in the $1000 \mathrm{ppm}$ group), two with fused ribs (one in the $1000 \mathrm{ppm}$ group and one in the $3000 \mathrm{ppm}$ group), one with missing vertebrae in the 1000 ppm group, and five with syndactyly all from a single litter in the 3000 ppm group. Although there was not a significant trend for an increase of malformations with respect to increasing concentration of MEK, the $3000 \mathrm{ppm}$ group did have a higher combined incidence of malformations than did either of the two lower exposure groups.

Gestational exposure to MEK resulted in a significant, treatment-related increase in the incidence of misaligned sternebrae with respect to the control group (Table 4). The increase (not statistically significant) in the mean percentage per litter of total variations was due mostly to the increase in misaligned sternebrae.

\section{DISCUSSION}

Exposure of pregnant Swiss (CD-1) mice to $0,400,1000$, or $3000 \mathrm{ppm}$ MEK did not result in apparent maternal toxicity, although an exposure-related increase in the relative liver-tobody-weight ratio was present and statistically significant at $3000 \mathrm{ppm}$ MEK. This increase in liver weight, above the increase normally observed during pregnancy, may be related to

TABLE 3

Methyl Ethyl Ketone Mouse Developmental Toxicity Study: IN UTERo DeVelopment

\begin{tabular}{lcccc}
\hline & \multicolumn{4}{c}{ Exposure group (ppm) } \\
\cline { 2 - 5 } & 0 & 400 & 1000 & 3000 \\
\hline Implantations/dam & $12.4 \pm 2.3^{a}$ & $12.2 \pm 2.2$ & $12.3 \pm 1.8$ & $12.3 \pm 1.8$ \\
Live fetuses/litter & $11.9 \pm 2.3$ & $11.3 \pm 2.5$ & $11.2+1.6$ & $11.5 \pm 1.9$ \\
Resorptions/litter & $0.5 \pm 0.8$ & $0.9 \pm 1.0$ & $1.1 \pm 1.1$ & $0.7 \pm 0.8$ \\
Dead fetuses/litter & 0 & $0.0 \pm 0.2$ & 0 & $0.1 \pm 0.3$ \\
Litters with resorptions & $9 / 26$ & $12 / 23$ & $16 / 26$ & $16 / 28$ \\
Fetal wt, male (g) & $1.38 \pm 0.07$ & $1.38 \pm 0.06$ & $1.34 \pm 0.10$ & $1.31 \pm 0.08^{*}$ \\
Fetal wt, female (g) & $1.32 \pm 0.08$ & $1.33 \pm 0.08$ & $1.31 \pm 0.06$ & $1.27 \pm 0.08$ \\
$\%$ males & $50 \pm 12$ & $47 \pm 13$ & $43 \pm 15$ & $51 \pm 18$ \\
No. live fetuses malformed/litter (\%) & $1(0.3)$ & $3(1.2)$ & $3(1.0)$ & $9(2.8)$ \\
No. litters with malformed fetuses (\%) & $1(3.8)$ & $3(13.0)$ & $3(11.5)$ & $5(17.9)$ \\
\hline
\end{tabular}

${ }^{a}$ Mean \pm SD.

* Significantly different from control, $p<0.05$. 
TABLE 4

Methyl Ethyl Ketone Mouse Developmental Toxicity Study: Malformations and Variations

\begin{tabular}{|c|c|c|c|c|c|c|c|c|}
\hline & \multicolumn{8}{|c|}{ Exposure group (ppm) } \\
\hline & 0 & 400 & 1000 & 3000 & 0 & 400 & 1000 & 3000 \\
\hline & \multicolumn{4}{|c|}{ No. fetuses ${ }^{a}$} & \multicolumn{4}{|c|}{ No. litters } \\
\hline Malformations & 310 & 260 & 291 & 323 & 26 & 23 & 26 & 28 \\
\hline Cleft palate & 0 & 2 & 1 & 0 & 0 & 2 & 1 & 0 \\
\hline Fused ribs & 0 & 0 & 1 & 1 & 0 & 0 & 1 & 1 \\
\hline Limb flexure & 1 & 1 & 0 & 3 & 1 & 1 & 0 & 3 \\
\hline Missing vertebrae & 0 & 0 & 1 & 0 & 0 & 0 & 1 & 0 \\
\hline Syndactyly & 0 & 0 & 0 & 5 & 0 & 0 & 0 & 1 \\
\hline \multicolumn{9}{|l|}{ Variations } \\
\hline Sternebrae & & & & & & & & \\
\hline misaligned & $31^{b}$ & 27 & 49 & 58 & 18 & 14 & 18 & 21 \\
\hline fused & 0 & 1 & 1 & 1 & 0 & 1 & 1 & 1 \\
\hline reduced ossification & 6 & 6 & 16 & 14 & 5 & 4 & 11 & 7 \\
\hline Supernumerary ribs & 56 & 44 & 58 & 65 & 17 & 13 & 15 & 22 \\
\hline Skull-reduced ossification & 3 & 3 & 2 & 5 & 2 & 2 & 2 & 2 \\
\hline
\end{tabular}

${ }^{a}$ All fetuses were examined for external and skeletal defects; one-half had head removed prior to skeletal staining for soft-tissue craniofacial evaluation. Visceral examinations were performed on approximately $50 \%$ of live fetuses and all fetuses with external defects.

${ }^{b}$ Significant trend, $p<0.05$.

enzyme induction as reported for rats by Toftgard et al. (1981). Developmental toxicity was observed in the present study in the form of a significant decrease in fetal body weight at $3000 \mathrm{ppm}$ MEK as well as a significant trend for an increase in the incidence of misaligned sternebrae, a skeletal variation. The incidence of fetal malformations in the MEK-exposed groups, although not statistically significantly different from control, is of some concern since several malformations were present which were not observed in concurrent or contemporary control groups of the same strain of mouse. The percentage of litters having fetuses with malformations was also greater for all MEK exposure groups than for the controls, although the differences were not statistically significant.

The results of this study in mice are reminiscent of those reported previously in two studies in Sprague-Dawley rats (Schwetz et al., 1974; Deacon et al., 1981) where major malformations were found in only the $3000 \mathrm{ppm}$ group. The relative sensitivity of rats and mice for an effect on fetal body weight is unclear since in the present study fetal body weight was significantly reduced at $3000 \mathrm{ppm}$ but not at lower concentrations; fetal rat weights were significantly reduced at the $1000 \mathrm{ppm}$ level but not at $3000 \mathrm{ppm}$ (Schwetz et al., 1974). Considering these three studies collectively, MEK caused developmental toxicity in the presence of mild maternal toxicity in rats and mice, and, in one rat study, in the absence of maternal toxicity.

The developmental toxicity of 2-butanol, a known metabolite of MEK, was investigated by Brightwell et al. (1987) in Sprague-Dawley rats. Pregnant females were exposed by inhalation to 3500,5000 , or $7000 \mathrm{ppm}$ 2-butanol, $7 \mathrm{hr} /$ day, throughout gestation until they were killed on Day 20. Maternal toxicity was evident at the highest concentration, as manifested by a reduction of weight and food consumption. There was no increase in the incidence of fetal malformations at any 
concentration of 2-butanol. A reduction in mean fetal body weight was observed at the $7000 \mathrm{ppm}$ concentration. Thus, at least one metabolite of MEK was not developmentally toxic even when administered at concentrations above those used for the parent compound in this study.

In summary, the results of this developmental toxicity study of inhaled methyl ethyl ketone in mice are similar to those reported earlier for rats; in both species, developmental toxicity has been observed in the presence of mild maternal toxicity, and a low incidence of malformations along with other evidence of developmental toxicity. In the present study in mice, no maternal or developmental toxicity was observed at concentrations of 1000 ppm MEK or below.

\section{ACKNOWLEDGMENTS}

This study was conducted at the Battelle Pacific Northwest Laboratory, operated for the U.S. Department of Energy by Battelle Memorial Institute. The study was done under contract to the National Toxicology Program (a related services agreement under Contract DE-ACU676RL0 1830). The authors express their appreciation to J. J. Evanoff, R. L. Romarine, and R. B. Westerberg for their expert assistance in the conduct of the study and to Mrs. Judy Bullard for her expertise in typing of the final manuscript for this publication.

\section{REFERENCES}

Abdel-Rahman, M. S., Hetland, L. B., and Couri, D. (1976). Toxicity and metabolism of methyl $n$-butyl ketone. Am. Ind. Hyg. Assoc. J. 37, 95-102.

ACGIH (1988). Threshold limit values and biological exposure indices for 1988-1989. American Conference of Governmental Industrial Hygienists.

AltenkirCH, H., StoltenburG, G., AND WaGner, H. M. (1978). Experimental studies on hydrocarbon neuropathies induced by methyl ethyl ketone (MEK). J. Neurol. 219, 159.
Brightwell, W. S., Nelson, B. K., Mackenzie-TayLOG, D. R., BURG, J. R., KHAN, A., AND GOAD, P. T. (1987). Lack of teratogenicity of three butanol isomers administered by inhalation to rats. Teratology 35, 56(A). Cavender, F. L., Casey, H. W., and Salem, H. (1983). A 90-day vapor inhalation toxicity study of methyl ethyl ketone. Fund. Appl. Toxicol. 3, 264-270.

Deacon, M. M., Pilny, M. D., AND John, J. A. (1981). Embryo- and fetotoxicity of inhaled methyl ethyl ketone in rats. Toxicol. Appl. Pharmacol. 59, 620-622.

Dietz, F. K., and Traiger, G. J. (1979). Potentiation of $\mathrm{CCl}_{4}$ hepatotoxicity in rats by a metabolite of 2-butanone: 2,3-Butanediol. Toxicology 14, 209-215.

DiVincenzo, G. D.. Kaplan, C. J.. And Dedinas, J. (1976). Characterization of the metabolites of methyl n-butyl ketone, methyl iso-butyl ketone, and methyl ethyl ketone in guinea pig serum and their clearance. Toxicol. Appl. Pharmacol. 36, 511-522.

Holmberg, P. C., AND NuRminen, M. (1980). Congenital defects of the central nervous system and occupational factors during pregnancy: A case-referent study. Am. $J$. Ind. Med. 1, 167-176.

MUNIES, R., AND WURSTER, D. E. (1965). Investigation of some factors influencing percutaneous absorption. IIl. J. of Pharma. Sci. 54(9), 1281-1284.

Perbellini, L., Burgnone, F., And Mozzo, P. (1984). Methyl ethyl ketone exposure in industrial workers: Uptake and kinetics. Int. Arch. Occup. Environ. Health 54, 73-81.

SANOYESHI, S. (1911). Uber zwei-butanolglycosaure. Biochem. Z. 36, 22.

SAS Institute, Inc. (1985). SAS User's Guide: Statistics, Sth edition. SAS Institute, Inc., Cary, NC.

SCHWETZ, B. A., LEONG, B. K. J., AND Gehring, P. J. (1974). Embryo- and fetotoxicity of inhaled carbon tetrachloride, 1,1-dichlornethane, and methyl ethyl ketone in rats. Toxicol. Appl. Pharmacol. 28, 452-464.

Toftgard, R., Nilsen, O. G., AND Gustafsson, J. A. (1981). Changes in rat liver microsomal cytochrome $P$ 450 and enzymatic activities after the inhalation of $n$ hexane, xylene, methyl ethyl ketone, and methylchloroform for four weeks. Scand. J. Work Environ. Health 7, 31-37.

WINER, B. J. (1971). Statistical Principles in Experimental Design. pp. 170-185. McGraw-Hill, New York.

YANG, R. S. H. (1986). The toxicology of methyl ethyl ketone. In Residue Reviews (F. A. Gunther and J. D. Gunther, Eds.), Vol. 97, pp. 212-243. Springer-Verlag, New York. 